\title{
Cellular localization of sphingomyelin synthase 2 in the seminiferous epithelium of adult rat testes
}

\author{
Nikki P Y Lee, Dolores D Mruk, Weiliang Xia and C Yan Cheng \\ Population Council, Center for Biomedical Research, 1230 York Avenue, New York, New York 10021, USA \\ (Requests for offprints should be addressed to C Y Cheng; Email: y-cheng@popcbr.rockefeller.edu) \\ (N P Y Lee is now at The Departments of Surgery and Medicine, Queen Mary Hospital, University of Hong Kong, Hong Kong, China)
}

\begin{abstract}
Sphingomyelin synthase 2 (SMS2) is an enzyme that catalyzes the conversion of phosphatidylcholine and ceramide to sphingomyelin and diacylglycerol, and it is crucial to cellular lipid metabolism. Using the technique of subtraction hybridization, we have isolated a full-length cDNA encoding SMS2 from rat testes, which shared 93 and $87 \%$ identity at the nucleotide level with SMS2 in mice and humans respectively. A specific polyclonal antibody was prepared against a 20 amino acid peptide of $\mathrm{NH}_{2}$-FSWPLSWPPGCFKSSCKKYS$\mathrm{COOH}$ near the C-terminus of SMS2. Studies by RT-PCR and immunoblotting have shown that the expression of SMS2 was limited to late round spermatids and elongating spermatids, but it was not detected in late elongate spermatids and Sertoli cells. Furthermore, SMS2 was shown to associate with the developing acrosome beginning in late round
\end{abstract}

spermatid through elongating spermatids (but not late elongate spermatids) and the cell membrane in studies using fluorescent microscopy and immunohistochemistry. These data were further confirmed by studies using immunogold electron microscopy. The expression of SMS2 in the seminiferous epithelium is stage-specific with its highest expression detected in the acrosome region in late round spermatids from stages VIII-IX, and also in the acrosome in elongating spermatids with diminished intensity in stages $\mathrm{X}-\mathrm{V}$; however, it was not found in the acrosome in elongate spermatids in stages VI-VIII. Collectively, these results suggest that SMS2 may play a crucial role in the lipid metabolism in acrosome formation and the plasma membrane restructuring from late round spermatids to early elongating spermatids.

Journal of Endocrinology (2007) 192, 17-32

\section{Introduction}

The testis is composed of two functional compartments: (i) the seminiferous tubules which are constituted by developing germ cells and Sertoli cells that are found behind the tunica propria and (ii) the Leydig cells in the interstitium, which carry out spermatogenesis and steroidogenesis respectively (Johnson et al. 1970, Russell et al. 1990). During spermatogenesis, spermatogonia residing at the basement membrane of the seminiferous epithelium differentiate into preleptotene spermatocytes, which traverse the blood-testis barrier (BTB) at stage VIII of the epithelial cycle (Russell 1977) and migrate towards the tubule lumen, while undergoing extensive cellular transformation (Lee \& Cheng 2004, Xia et al. 2005). This process of germ cell development and cellular movement is mediated through precise coordination between the developing germ cells and the Sertoli cells in the seminiferous epithelium, since the BTB has physically segregated post-meiotic germ cells from nutrients and biomolecules in the systemic circulation (Russell 1980, Mruk \& Cheng 2004b).

As part of our ongoing efforts to study the Sertoli-germ cell interactions, we have used the techniques of subtraction hybridization to identify germ cell-specific antigens. Unexpectedly, we isolated a full-length cDNA that was shown to be sphingomyelin synthase 2 (SMS2) with its expression limited to late round spermatids and elongating spermatids, but is not found in late elongate spermatids or Sertoli cells. It is known that SMS2 is an enzyme that catalyzes the bidirectional conversion of the phosphatidylcholine (PC) and the ceramide to sphingomyelin (SM) and diacylglycerol (DAG) and vice versa (Huitema et al. 2004, Perry \& Ridgway 2005), and it is vital to lipid metabolism in eukaryotic cells. SMS2 and its enzymatic activity have been extensively investigated in other systems, such as in chick liver (Lyman et al. 1976), rat colon (Dudeja et al. 1986), and mouse ascitic cells (Marggraf \& Kanfer 1987). Recently, a family of SMS was identified in humans which was shown to have diversified functions (Huitema et al. 2004). However, the presence of SMS2 in the testis has not been described, yet there are published findings in the literature reporting the presence of SM in the Sertoli cells in the testis (Ziulkoski et al. 2001a,b). For instance, two SMs were reported to be synthesized at the Golgi apparatus and the plasma membrane in the Sertoli cells (Ziulkoski et al. $2001 a, b)$. 
In this paper, we report recent findings from our laboratory on the spatial distribution and cellular association of SMS2 as well as its stage-specificity in the seminiferous epithelium of adult rat testes. These results will become the basis for future investigation that tackles the functional significance of SMS2 and its related enzymes in spermatogenesis.

\section{Materials and Methods}

\section{Animals}

Sprague-Dawley rats and New Zealand white (female) rabbits were purchased from Charles River Laboratories (Kingston, NY, USA). The use of animals in this study was approved by The Rockefeller University Animal Care and Use Committee with Protocol Numbers 00111, 03017, 03040, and 06018. All animals were housed at The Rockefeller University Laboratory Animal Research Center with a ratio of $12 \mathrm{~h}$ light: $12 \mathrm{~h}$ darkness at $20 \pm 1{ }^{\circ} \mathrm{C}$ with free access to water and standard chow.

\section{Primary cultures of the Sertoli and the germ cells}

The Sertoli cells were isolated from testes of $20-, 45-$, and 90-day-old rats and cultured in serum-free Ham's F12 Nutrient mixture/Dulbecco's Modified Eagle's medium (F12/DMEM) media supplemented with bovine insulin $(5 \mu \mathrm{g} / \mathrm{ml})$, human transferrin $(5 \mu \mathrm{g} / \mathrm{ml})$, epidermal growth factor $(2.5 \mathrm{ng} / \mathrm{ml})$, gentamicin $(20 \mu \mathrm{g} / \mathrm{ml})$, and bacitracin $(10 \mu \mathrm{g} / \mathrm{ml})$ at $35^{\circ} \mathrm{C}$ in a humidified environment with $95 \%$ air $/ 5 \% \mathrm{CO}_{2}(\mathrm{v} / \mathrm{v})$ as described earlier (Lee \& Cheng 2003, Lee et al. 2003). Approximately $36 \mathrm{~h}$ thereafter, cells were subjected to a hypotonic treatment using $20 \mathrm{mM}$ Tris $\mathrm{pH} 7 \cdot 4$ at $22{ }^{\circ} \mathrm{C}$ for $2 \mathrm{~min}$ to lyze any residual germ cells (Galdieri et al. 1981). Celluar debris were then removed by washing Sertoli cells on dishes twice with media and Sertoli cells were cultured in F12/DMEM with supplements for an additional $24 \mathrm{~h}$ before their termination for either RNA extraction on lysate preparation. Freshly isolated total germ cells from testes of 20-, 45-, 60-, and 90-day-old rats in F12/DMEM supplemented with sodium pyruvate $(2 \mathrm{mM})$, sodium lactate $(6 \mathrm{mM})$, and gentamicin $(20 \mu \mathrm{g} / \mathrm{ml})$ were used within $4 \mathrm{~h}$ as described (Lee \& Cheng 2003, Lee et al. 2003). These primary Sertoli and germ cells were shown to have a purity of greater than $98 \%$ when examined microscopically and found to have negligible contamination of other cell types when assessed by RT-PCR and immunoblotting using markers specific to the Sertoli cells (e.g. testin), the germ cells (e.g. c-kit receptor), the Leydig cells ( $3 \beta$-hydroxysteroid dehydrogenase), and the peritubular myoid cells (e.g. fibronectin) as described (Lee et al. 2004). To obtain germ cell-conditioned medium (GCCM), germ cells isolated from testes of 90-dayold rats were cultured for $16 \mathrm{~h}$ and spent media were collected after centrifugation $(800 \boldsymbol{g}, 10 \mathrm{~min})$ to remove germ cells as described (Mruk et al. 1997).

\section{Isolation of seminiferous tubules}

Seminiferous tubules were isolated from adult rat testes and cultured as previously described (Lee \& Cheng 2003, Lee et al. 2003). In brief, testes were decapsulated, seminiferous tubules were separated by enzymatic digestion with collagenase/dispase $(0 \cdot 05 \%, \mathrm{w} / \mathrm{v})\left(25 \mathrm{~min}\right.$ at $\left.35^{\circ} \mathrm{C}\right)$ using tubules released from one testis per $25 \mathrm{ml} \mathrm{F12/DMEM.} \mathrm{Interstitial} \mathrm{cells} \mathrm{were} \mathrm{removed} \mathrm{by}$ extensive washing of the tubules in F12/DMEM by sedimentation under gravity. Tubules were incubated for $4 \mathrm{~h}$ at $35^{\circ} \mathrm{C}$ with $95 \%$ air $/ 5 \% \mathrm{CO}_{2}(\mathrm{v} / \mathrm{v})$ and washed twice every $2 \mathrm{~h}$ to remove steroids released by the tubules. Tubules were then trimmed into $2 \mathrm{~mm}$ pieces with a sterile scalpel and incubated for $48 \mathrm{~h}$ at $35^{\circ} \mathrm{C}$ in F12/DMEM supplemented with insulin $(20 \mu \mathrm{g} /$ $\mathrm{ml})$, transferrin $(20 \mu \mathrm{g} / \mathrm{ml})$, gentamicin $(100 \mu \mathrm{g} / \mathrm{ml})$, and penicillin $(100 \mathrm{IU} / \mathrm{ml})$. Thereafter, tubules were used for RNA extraction for subtractive hybridization experiment. Staged tubules were also isolated from adult rat testes by transillumination stereomicroscopy as described (Chen et al. 2003).

\section{$R N A$ isolation and protein extraction}

RNA isolation was performed using RNA STAT-60 (Tel-Test, Inc., Friendswood, TX, USA) according to the manufacturer's instructions. For protein extraction, frozen tissues, tubules, or cells were sonicated or homogenized on ice in the lysis buffer (20 mM Tris, $0 \cdot 15 \mathrm{M} \mathrm{NaCl}, 1 \mathrm{mM}$ EGTA, $1 \mathrm{mM}$ phenylmethylsulphonyl fluoride, $1 \% \mathrm{NP}-40$, $\mathrm{pH} 7 \cdot 4$ at $22^{\circ} \mathrm{C}$ ) to be followed by centrifugation $\left(15000 \mathrm{~g}, 30 \mathrm{~min}\right.$ at $\left.4{ }^{\circ} \mathrm{C}\right)$ and the clear supernatants were collected as total protein lysates. Protein concentration was estimated by Coomassie blue dyebinding assay using bovine serum albumin (BSA) as a standard (Bradford 1976).

\section{Subtractive hybridization and cloning of SMS2}

A PCR-Select cDNA Subtraction kit obtained from Clontech (Palo Alto, CA, USA) was used to identify differentially expressed mRNA from two populations of mRNAs using an approach as earlier described (Glienke et al. 2000, Martin \& Pardee 2000) and the detailed protocols provided by the manufacturer without any modifications. A population (the tester) of mRNAs that have differentially expressed genes were compared with another (the driver) according to the instructions provided by the manufacturer. Total RNA isolated from the seminiferous tubules of the testes from adult rats (approximately $300 \mathrm{~g}$ body weight (b.w.) served as the tester RNA, and total RNA of the driver was obtained using RNAs isolated from the Sertoli cells with purity greater than 98\%. mRNA was isolated from total RNA using a PolyATract mRNA isolation system from Promega. After subtractive hybridization, differentially expressed cDNAs were directly ligated into pGEM-T vector (Promega). About 30-50 clones 
were selected and expanded for subsequent nucleotide sequencing analysis (Cheng et al. 2003). The resulting sequences were compared with the existing sequences at GenBank using the Basic Local Alignment Search Tool (BLAST). Novel sequences were selected for their use in additional experiments. Rat testis cDNA libraries were constructed using total RNA extracted from adult rat testes. Using the T7 and SP6 primers and the pGEM-T vector with the cDNA insert, the $5^{\prime}$ - and $3^{\prime}$-coding sequences were obtained by direct nucleotide sequencing.

\section{Reverse transcription-PCR (RT-PCR)}

Total RNA obtained from tissues or testicular cells were reverse transcribed as previously described (Lee \& Cheng 2003, Lee et al. 2003) using Moloney Murine leukemia virus $(\mathrm{M}-\mathrm{MLV})$ reverse transcriptase (Promega) and oligo $(\mathrm{dT})_{15}$ primers (Gene Link Inc., Hawthorne, NY, USA). PCR was performed as described using a primer pair specific to SMS2 (Lee \& Cheng 2003, Lee et al. 2003) and was co-amplified with S16 (Table 1). Preliminary experiments were performed using different concentrations of RT product and SMS2 primer pair versus S16, so that the production of both SMS2 and S16 was in their linear phase. Nonetheless, most of the RT-PCR data were verified by immunoblotting since an antiSMS2 antibody was available (see below).

\section{Production of a specific anti-SMS2 polyclonal antibody}

A 20 amino acid peptide of $\mathrm{NH}_{2}$-FSWPLSWPPGCFKSSCKKYS-COOH ( $\mathrm{Mr} 2335 \cdot 75$ ), corresponding to residues 333-352 from the $\mathrm{N}$-terminus of SMS2 was synthesized and obtained from Sigma Genosys. This stretch of sequence near the C-terminus of SMS2 was shown to be specific to SMS2 that shared limited homology with SMS1 or other proteins as verified against the database at GenBank using BLAST search. Following its purification by reversed-phase high performance liquid chromatography (HPLC), it was conjugated to keyhole limpet hemocyanin, which served as an adjuvant. A polyclonal antibody was prepared in a New Zealand female rabbit using procedures as earlier described (Mruk \& Cheng 1999). IgG was isolated from serum as described (Cheng et al. 1988). For isolation of IgG preimmune serum, about $2 \mathrm{ml}$ serum obtained from the same rabbit prior to immunization of the antigen was used, which served as controls in the experiments reported herein.

Treatment of rats with Adjudin - an in vivo model to study adherens junction (AJ) dynamics

Adjudin, formerly called Angelini Francesco (AF)-2364 [1(2,4-dichlorobenzyl-1H-indazole-3-carbohydrazide] is an analog of lonidamine that was selected from two dozen new compounds in earlier studies from our laboratory (Cheng et al. 2001), which is known to induce adherens junction disruption in adult rat testes (for a review, see Mruk \& Cheng 2004b). Recent studies have shown that Adjudin perturbed Sertoli-germ cell adhesion in the seminiferous epithelium of adult rat testes by exerting its effects most predominantly at the apical ectoplasmic specialization (apical ES) (note: apical ES is a testis-specific cell-cell actin-based AJ type) at the Sertoli cell-elongating/elongate spermatid interface, to be followed by disruption of junctions at the Sertoli cellspermatocyte interface (Cheng \& Mruk 2002, Chen et al. 2003). Apparently, junctions at the Sertoli cell-spermatogonia were not affected, since if spermatogonia were depleted from the epithelium, the transient infertility induced by Adjudin treatment would have been irreversible (Cheng et al. 2001; for a review, see Lee \& Cheng 2004). As such, the Adjudininduced germ cell loss from the epithelium in adult rats has been used as an in vivo model to study anchoring junction dynamics pertinent to spermatogenesis (Lee et al. 2003, Mruk et al. 2003, Siu et al. 2003). Furthermore, many of the findings obtained from this model has recently been validated using a similar model for studying anchoring junction dynamics involving the use of steroid implants to suppress intratesticular androgen level (Wong et al. 2005, Zhang et al. 2005). Since preliminary studies by immunogold EM have shown that SMS2 was found at the plasma membrane surrounding the developing acrosome, which also coincided with the site of apical ES, we sought to investigate if there were any changes in the level of SMS2 and its cellular localization in the testis during Adjudin-induced AJ restructuring. It is obvious that this event involves extensive plasma membrane turnover and restructuring because of the disruption of the apical ES to facilitate spermatid loss from the seminiferous epithelium. Adjudin used in this study was synthesized and characterized as earlier described (Cheng \& Mruk 2002). Adult rats weighing between 300 and $350 \mathrm{~g}$ were used for this study

Table 1 Primers used for RT-PCR to assess the steady-state mRNA levels of SMS2 in cells and testes and its co-amplification with S16

\begin{tabular}{|c|c|c|c|c|c|c|}
\hline & Primer sequence & Orientation & Position & Length & Annealing temperature & Reference \\
\hline \multicolumn{7}{|l|}{ Target gene } \\
\hline S16 & 5'-TCCGCTGCAGTCCGTTCAAGTCTT-3' & $\begin{array}{l}\text { Sense } \\
\text { Antisense }\end{array}$ & $\begin{array}{c}15-38 \\
379-399\end{array}$ & 385 & $58^{\circ} \mathrm{C}$ & Chan et al. 1990 \\
\hline SMS2 & $\begin{array}{l}5^{\prime} \text {-ATGTACGTCACTACG-3' } \\
5^{\prime} \text {-AGGAAGTCTCCACAC-3' }\end{array}$ & $\begin{array}{l}\text { Sense } \\
\text { Antisense }\end{array}$ & $\begin{array}{l}520-534 \\
660-674\end{array}$ & 155 & $58^{\circ} \mathrm{C}$ & DQ071571 \\
\hline
\end{tabular}


A

gi| 55250053 |gb|AAH85803.1|RAT gi|44888533|sp|Q9D4B1|SMS2 MOU gi| 44888519 |sp|Q8NHU3|SMS2_HUM

gi| 55250053 |gb|AAH85803.1|RAT gi|44888533|sp|Q9D4B1|SMS 2 MOU gi| 44888519 |sp|Q8NHU3 |SMS2 HUM

gi 55250053 |gb| AAH 85803.1 |RAT gi|44888533|sp|Q9D4B1|SMS2_MOU gi 44888519 |sp|Q8NHU3 |SMS2_HUM

gi|55250053|gb|AAH85803.1|RAT gi|44888533|sp|Q9D4B1|SMS2 MOU gi | 44888519 | sp | Q8NHU3|SMS2_HUM

gi| 55250053 |gb|AAH85803.1|RAT gi|44888533|sp|Q9D4B1|SMS2_MOU gi| 44888519 |sp|Q8NHU3 |SMS2_HUM

gi|55250053|gb|AAH85803.1|RAT gi|44888533|sp|Q9D4B1|SMS2 MOU gi| 44888519 |sp|Q8NHU3|SMS2_HUM

gi|55250053|gb|AAH85803.1|RAT gi| 44888533 |sp|Q9D4B1|SMS 2 MOU gi| 44888519 |sp|Q8NHU3 |SMS2_HUM

gi|55250053|gb|AAH85803.1|RAT gi|44888533|sp|Q9D4B1|SMS2 MOU gi 44888519 |sp|Q8NHU3 |SMS2_HUM
MDI IETAKLEGHLESQTNNSTNTYTSPTEAVEEEDKNGKGKPKTLSNGLR 50 MDI IETAKLEGH LESQTNDSTNTYTSPTEAVEEEGKNGKGKPKTLSNGLR 50 MDI IETAKLEEHLENQPSDPTNTYARPAEPVEEENKNGNGKPKSLSSGLR 50

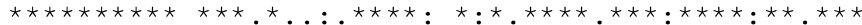

KGAKKYPDYIOISMPNDSRNKLPLEWWKTGIAFVYALFNLILTTVMITVV 100 KGAKKYPDYIQISMPNDSKNKFPLEWWKTGIAFVYALFNLILTTVMITVV 100 KGTKKYPDYIQIAMPTESRNKF PLEWWKTGIAFIYAVFNLVLTTVMITVV 100

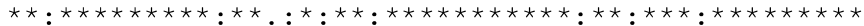

HERVPPKELSPPLPDKFFDYVDRVKWAFSVSE INGMVLVGLWLTOWLFLR 150 HERVPPKELSPP LPDKFFDYFDRVKWAFSVSE INGMVLVGLWITQWLFLR 150 HERVPPKELSPP LP DKFFDYIDRVKWAFSVSE INGI I LVGLWITQWLFLR 150

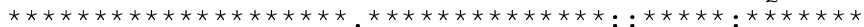

YKS IVGRRFFFIMGTLYLYRCI TMYVTTLPVPGMHFOCAPKLNGDSOAKI 200 YKSIVGRRFFFIMGTLYLYRCITMYVTTLPVP GMHFQCAPKLNGDSQAKI 200 YKS IVGRRFCFI IGTLYLYRCI TMYVTTLPVP GMHFQCAPKLNGDSQAKV 200

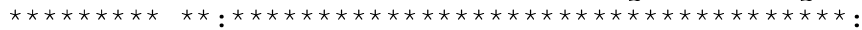

QRILRLLSGGGLSITGSHILCGDFLFSGHTVVLTLTYLFIKEYSPRHFWW 250 QRILRLI SGGGLSITGSHILCGDFLFSGHTVVLTLTYLFIKEYSPRHFWW 250 QRILRLISGGGLSITGSHILCGDFLFSGHTVTLTLTYLFIKEYSPRHFWW 250

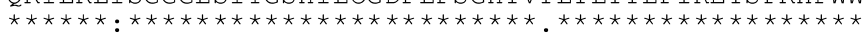

YHLVCWLLSAAG IVCILVAHEHYTVDVI IAYYITTRLFWWYHSMANEKNL 300 YHLVCWLLSAAG I I I I LVAHEHYTVDV I IAYY ITTRLFWWYH SMANEKNL 300 YHLICWLLSAAG I I ILVAHEHYT IDVI IAYYITTRLFWWYHSMANEKNL 300

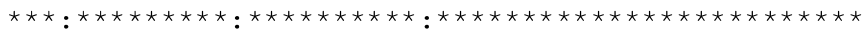

KVSSQTNFLSRAWWFPIFYFFEKNVQGS I PCCFSWPLSWPPGCFKSSCKK 350 KVSSOTNFLSRAWWFPIFYFFEKNVOGS I PCC FSWPLSWPPGCFKSSCRK 350 KVSSQTNELSRAWWFPIFYFFEKNVQGS I PCCFSWPLSWPPGCFKSSCKK 350

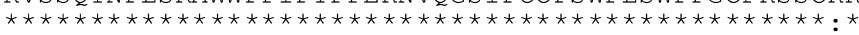

YSRVQKIGEDNEKST 365

YSRVOKIGEDNEKST 365 YSRVQKIGEDNEKST 365

Figure 1 (continued)

\begin{tabular}{|c|c|c|c|c|}
\hline & & \multicolumn{3}{|c|}{ Nucleotide Homology (\%) } \\
\hline & & Rat & Mouse & Human \\
\hline \multirow{3}{*}{ 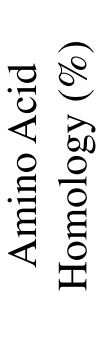 } & Rat & - & $93 \%$ & $87 \%$ \\
\hline & Mouse & $97 \%$ & - & $85 \%$ \\
\hline & Human & $90 \%$ & $91 \%$ & - \\
\hline
\end{tabular}




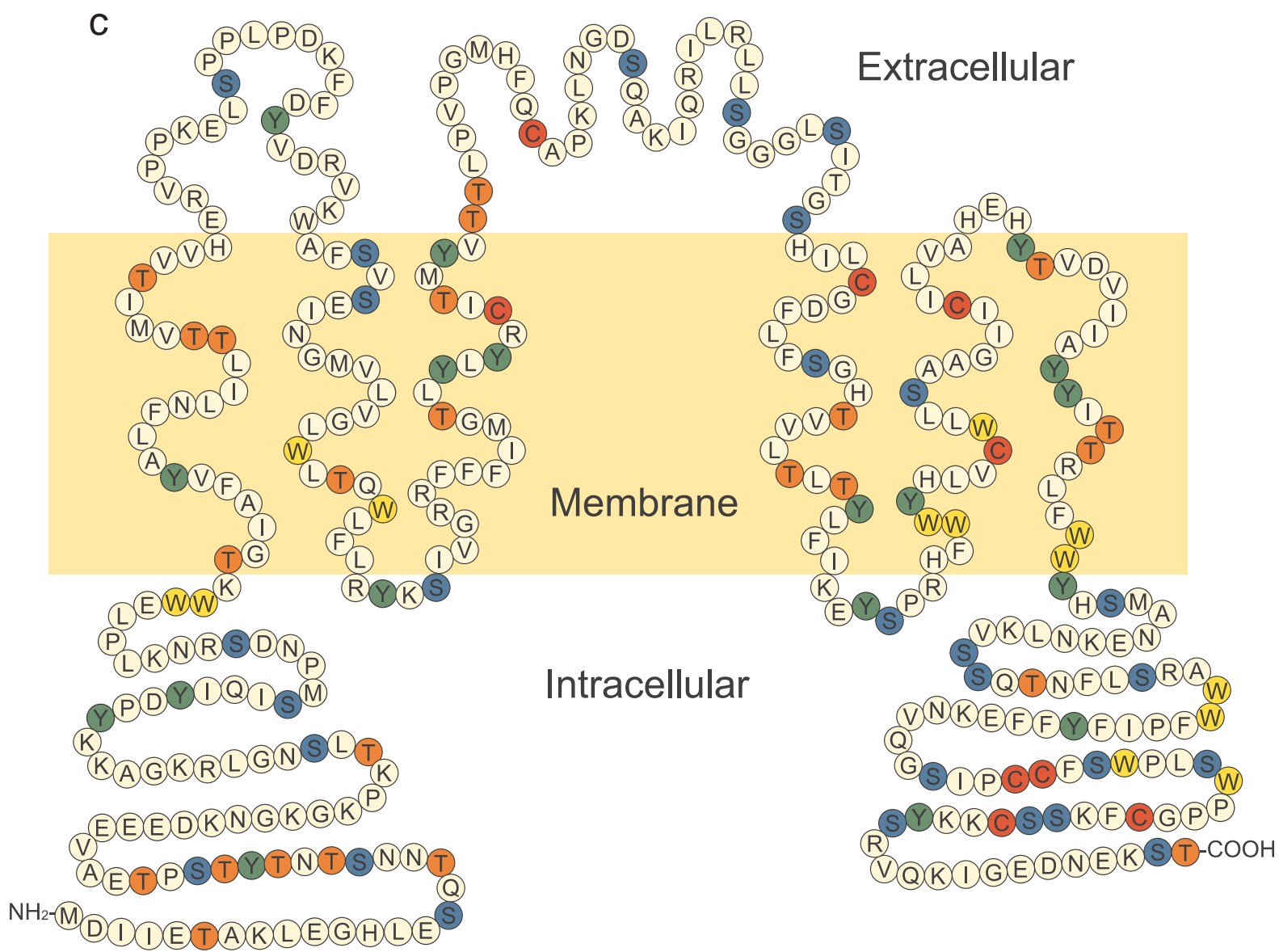

Figure $1(\mathrm{~A}-\mathrm{C})$ Characterization of the full-length SMS2 CDNA clone and its translated amino acid sequence. The nucleotide sequence of the full-length rat SMS2 clone was determined and the translated amino acid sequence of the open reading frame is shown in (A). The three amino acid sequences of SMS2 from rats, mice (mou), and humans (hum) were aligned using ClustalW (A). The percentage homology of the nucleotide and amino acid sequences of SMS2 in rats, mice, and humans were shown in (B). (C) Graphical presentation of the rat SMS2 amino acid sequence. The transmembrane domains of the SMS2 primary sequence are embedded in the shaded membrane region. Three extracellular loops and four intracellular loops are also shown. The $\mathrm{N}$-terminus $\left(\mathrm{NH}_{2}-\right)$ and the $\mathrm{C}$-terminus $(-\mathrm{COOH})$ are also illustrated. Trp $(\mathrm{W})$ that confers the tertiary structure is colored yellow; Cys $(\mathrm{C})$ that confers secondary structure through the formation of disulfide bonds is colored red. Thr (T), $\operatorname{Ser}(\mathrm{S})$, and $\operatorname{Tyr}(\mathrm{Y})$, the putative phosphorylation sites for the action of protein kinases and phosphatases are represented by orange, blue, and green respectively. The predicted primary structure of SMS2 was prepared based on previous studies (Huitema et al. 2004, Tafesse et al. 2006) and the locations of the transmembrane domains were estimated using the on-line TMHMM program.

with a group of three animals per time point. The rats were orally fed with $50 \mathrm{mg}$ Adjudin per kilogram body weight as described (Lee \& Cheng 2005). Thereafter the rats were killed by $\mathrm{CO}_{2}$ asphyxiation at specified time points and testes were collected (Mruk \& Cheng 2004a). Testes were snap-frozen in liquid nitrogen and stored at $-80{ }^{\circ} \mathrm{C}$ until used for protein extraction or for immunofluorescent microscopy.

\section{Immunogold electron microscopy (immunogold EM)}

Immunogold electron microscopy was performed at The Rockefeller University Bio-Imaging Resource Center. In brief, testes were fixed in ice-cold $4 \%$ paraformaldehyde and $0 \cdot 1 \%$ glutaraldehyde in $0 \cdot 1 \mathrm{M}$ cacodylate buffer, $\mathrm{pH} 7 \cdot 4$.
The samples were dehydrated with ascending graded ethanol and then embedded in Epon 812. Semi-thin sections $(0 \cdot 5 \mu \mathrm{m})$ were cut with a glass knife and stained with $0 \cdot 25 \%$ toluidine blue in $1 \%$ sodium borate for their examination under light microscope, so that the samples were orientated such that cross-sections of multiple tubules could be obtained. Thereafter, tissue blocks were re-trimmed, ultra-thin sections obtained with a DuPont diamond knife, and sections were collected on copper grids and incubated with anti-SMS2 IgG or pre-immune IgG (control) at room temperature overnight. This was followed by incubation with $10 \mathrm{~nm}$ gold-labeled goat-anti-rabbit $\operatorname{IgG}$ secondary antibody. Sections were then stained with uranyl acetate and lead citrate and examined in a JEOL $100 \mathrm{CX}$ electron microscope operated at $80 \mathrm{kV}$. 
Immunoreactive SMS2 appeared as 'black dots' in EM micrographs.

\section{Immunofluorescent microscopy}

Testes isolated from adult rats were frozen immediately in liquid nitrogen and stored at $-80{ }^{\circ} \mathrm{C}$ so that all the samples within a treatment group could be processed simultaneously in an experimental session. Sections of $10 \mu \mathrm{m}$ in thickness were cut in a cryostat and collected on poly-L-lysine-coated slides. After equilibration to room temperature, sections were fixed in Bouin's fixative before blocking with $10 \%$ normal goat serum $(\mathrm{v} / \mathrm{v}$ in PBS) for $1 \mathrm{~h}$ at room temperature. Sections were incubated with rabbit anti-SMS2 antibody (1:400 in blocking solution) at $4{ }^{\circ} \mathrm{C}$ overnight. Fluorescein isothiocyanate (FITC) conjugated goat anti-rabbit antibody (Invitrogen; 1:20 in blocking solution) was used as a secondary antibody and incubation was carried out at $37^{\circ} \mathrm{C}$ for $1 \mathrm{~h}$. For the detection of N- and E-cadherins, Cy3labeled secondary antibodies (Invitrogen-Zymed) were used instead. 4',6-Diamidino-2-phenylindole, dihydrochloride (DAPI; Molecular Probes, Eugene, OR, USA) was used as a counterstain to visualize cell nuclei. Sections were viewed and Images were captured under an Olympus BX-40 microscope (Olympus Corp., Melville, NY, USA) with Olympus UPlanF1 fluorescent optics and an Olympus DP70 12.5 MPa digital camera respectively. Images were acquired using the QImaging QCapture Suite (Version 2.6) software package (Quantitative Imaging Corp, Burnaby, BC, Canada) and analyzed using Adobe PhotoShop (Version 7.0).

\section{Bioinformatics analysis}

cDNA sequence of SMS2 was translated into its amino acid sequence using Translate tool in the Expert Protein Analysis System (ExPASy) Proteomics Server (http://au.expasy.org/). In addition, putative serine/tyrosine/threonine phosphorylation sites, tyrosine sulfation sites, and glycosylation sites were predicted using NetPhos (Blom et al. 1999), Sulfinator (Monigatti et al. 2002) and NetOGlyc (Julenius et al. 2005) available in ExPASy. SignalP (Bendtsen et al. 2004) in ExPASy was used as a tool to search for signal peptide sequence in SMS2. Transmembrane domains were determined using the transmembrane helix prediction (TMHMM) Program (Moller et al. 2001) in ExPASy. Chromosomal location of SMS2 was revealed by BLAST using Entrez Genomes Map Viewer (available in http://ncbi.nlm.nih.gov/). Homologous proteins were matched using protein-protein BLAST (blastp) and conserved domains were searched using rpsblast, provided by National Center for Biotechnology Information (NCBI). Simple Modular Architecture Research Tool (SMART; Schultz et al. 1998), offered by the European Molecular Biology Laboratory-European Bioinformatics Institute (EMBL-EBI) from European Bioinformatics Institute (http://www.ebi.ac.uk/), was used to identify putative signaling domains.

\section{Results}

Sequence analysis and bioinformatics analysis of SMS2

A 1098 bp cDNA clone encoding the entire open reading frame of rat SMS2 of 365 amino acid residues was obtained from rat testes using the technique of subtractive hybridization as described in Materials and Methods. The sequence of the SMS2 cDNA clone was determined by nucleotide sequencing analysis using sequence- and vectorspecific primers. The translated amino acid sequence is shown in Fig. 1A. The identity of the nucleotide sequence was verified against the database at GenBank using BLAST, a search and comparison software package. The sequence of this $1098 \mathrm{bp}$ rat testicular cDNA clone has been deposited at GenBank with Accession Number DQ071571 and designated rat SMS2 because of its homology with mouse and human SMS2. For instance, rat SMS2 nucleotide sequence shared 93 and $87 \%$ homology with mouse and human counterparts respectively (Fig. 1B). This $1098 \mathrm{bp}$ cDNA was used to search for its chromosomal location using Entrez Genomes Map Viewer by BLAST; it was found that rat SMS2 was located on chromosome 2. The amino acid sequence was subsequently used to obtain sequence- and protein-related information using software available at NCBI, EMBL-EBI, and ExPASy as described in Materials and Methods. Rat SMS2 is composed of 365 amino acid residues (Fig. 1A) with a calculated $\mathrm{Mr}$ of $42 \mathrm{kDa}$ and a $\mathrm{pI}$ of $9 \cdot 1$. Using protein-protein BLAST (blastp) to search for protein homology, mouse (GenBank Accession Number, Q9D4B1) and human (GenBank Accession Number, Q8NHU3) SMS2 were shown to share 97 and $90 \%$ amino acid sequence identity with rat SMS2 respectively (Fig. 1B). The amino acid sequences of these SMS2 proteins from three species were aligned using ClustalW (Fig. 1A) and the percentage homology of them was tabulated in Fig. 1B. Structurally, SMS2 was composed of six transmembrane domains (Fig. 1C) and a low compositional complexity region (ILRLLSGGGLSITGSHIL) partially overlapped with the fourth transmembrane domain (Fig. 1C), which was obtained by analogous comparison with known molecules of similar structure using the on-line TMHMM program. No signal peptide was found, suggesting that it is a non-secretory protein. There were eight putative Ser phosphorylation sites, two putative Thr phosphorylation sites, and four Tyr phosphorylation sites in SMS2, however, no Tyr sulfation and putative glycosylation sites were identified (Fig. 1C). Also, no putative conserved domain was detected using the rpsblast and SMART.

\section{Cellular expression of SMS2 in the seminiferous epithelium of rat testes}

The cellular expression of SMS2 was investigated by semiquantitative RT-PCR (Fig. 2). While SMS2 was found in the 
A

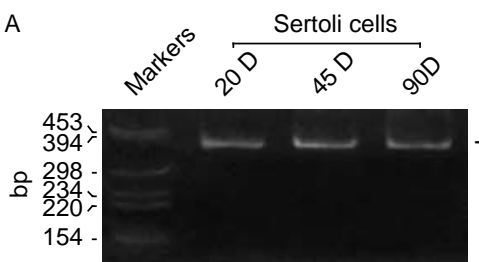

C

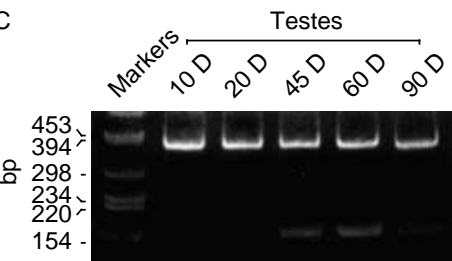

B

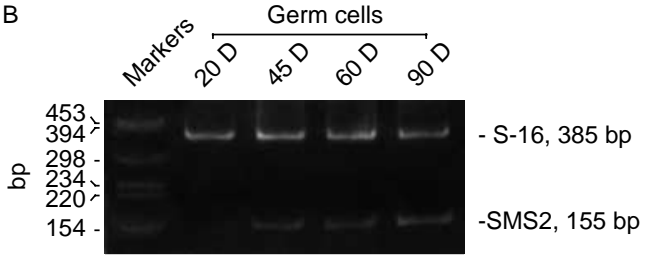

D

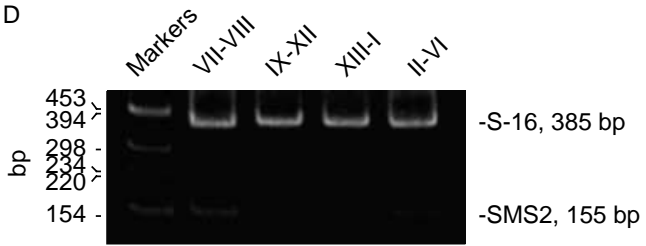

Figure 2 (A-D) Relative steady-state mRNA level of SMS2 in cells of the seminiferous epithelium. Testicular cells, such as Sertoli cells (A) and germ cells (B), testes (C) and staged tubules (D) were obtained from rats at different ages. RNA was isolated and RT-PCR was performed to investigate the relative steady-state mRNA levels of SMS2. S-16 served as a loading control. Representative gel images from three separate experiments using three different sets of rats are shown. D, day.

testis, it was restricted almost exclusively to germ cells, since SMS2 was not detected in the Sertoli cells isolated from the testes of rats at 20, 45, and 90 days of age (Fig. 2A versus B). The steady-state mRNA level of SMS2 in germ cells increased with age, since it was barely detectable in germ cell RNA from 20-day-old rats (Fig. 2B), and this pattern was consistent with its expression level in testes (Fig. 2C versus B). These results are also in agreement with immunohistochemistry data since SMS2 was shown to predominantly associate with developing spermatids at the acrosomes and testes from 10- and 20-day-old rats did not contain round and elongating spermatids (see below). Using staged tubules isolated from adult rat testes for RNA extraction and for RT-PCR, it was shown that the expression of SMS2 is stage-specific, being highest in stages II-VIII and very low expression in stages IX-I (Fig. 2D).

Localization of SMS2 in the seminiferous epithelium of adult rat testes - a study by immunohistochemistry, immunofluorescence microscopy, and immunogold electron microscopy

Antibody characterization A polyclonal antibody against a stretch of sequence of SMS2 near the C-terminus at the fourth intracellular domain (see Fig. 1C) was generated in a rabbit. When this stretch of sequence, amino acid residues 333-352 from the N-terminus of SMS2, was compared with protein database at GenBank using the BLAST search program, 100\% homology was obtained with SMS2 and hypothetical protein LOC310849 (which is the former name of SMS2), and no identity was found with SMS1 (see Fig. 3A) except it displayed 8\% homology with nicotinic acetylcholine receptor $\alpha 3$ subunit. However, when this stretch of sequence, residues 333-352, was compared against the entire SMS1 sequence using PROSIS through forced comparison, approximately $40 \%$ homology was obtained with residues 395-413 in SMS1, but only if there was an insertion of an extra amino acid between residues 402 and 403 (see Fig. 3A). As such, this unremarkable similarity between SMS1 and SMS2 (note: the entire primary sequences between SMS1 and SMS2 share $<60 \%$ homology) at this stretch of sequence is not likely to generate an antibody that would cross-react between SMS2 and SMS1. The specificity of this antibody was shown in Fig. 3B by immunoblotting using the anti-SMS2 IgG. This antibody essentially detected only a prominent band of approximately $55 \mathrm{kDa}$ in the lysates of germ cells, seminiferous tubules, and testes as well as the brain, but not Sertoli cells (Fig. 3B). Thus, these results are consistent with the data of RT-PCR, illustrating the SMS2 protein was not detected in the Sertoli cells, but restricted to the germ cells in the seminiferous epithelium. SMS2 apparently was composed of two molecular variants of approximately 54 and $56 \mathrm{kDa}$ (see Fig. 3B).

Immunohistochemistry This antibody was subsequently used for immunohistochemistry to examine the localization of SMS2 in the seminiferous epithelium of adult rat testes as shown in Fig. 3C and D. SMS2 was most abundantly associated with the acrosomal region in developing round spermatids at stages VII, VIII, and IX, and also with elongating spermatids in stages XIV-V, but its presence in elongate spermatids at stages VII-VIII was greatly diminished (see Fig. 3C and D). Only very weak staining of SMS2 was detected in late elongate spermatids in stages V-VIII tubules (see Fig. 3D). Immunoreactive SMS2 was also detected in the interstitium and was shown to associate with Leydig cells. No positive signal was detected in negative control using IgG isolated from pre-immune serum from the same rabbit that was used for antibody production before immunization to substitute the anti-SMS2 IgG for immunohistochemistry 
A

gi46371580/gb AAS90514.1 (SMS1)
gi89363045/gb AAY84706.2 (SMS2)
gb DQ071571
gi46371580/gb AAS90514.1 (SMS1)

B

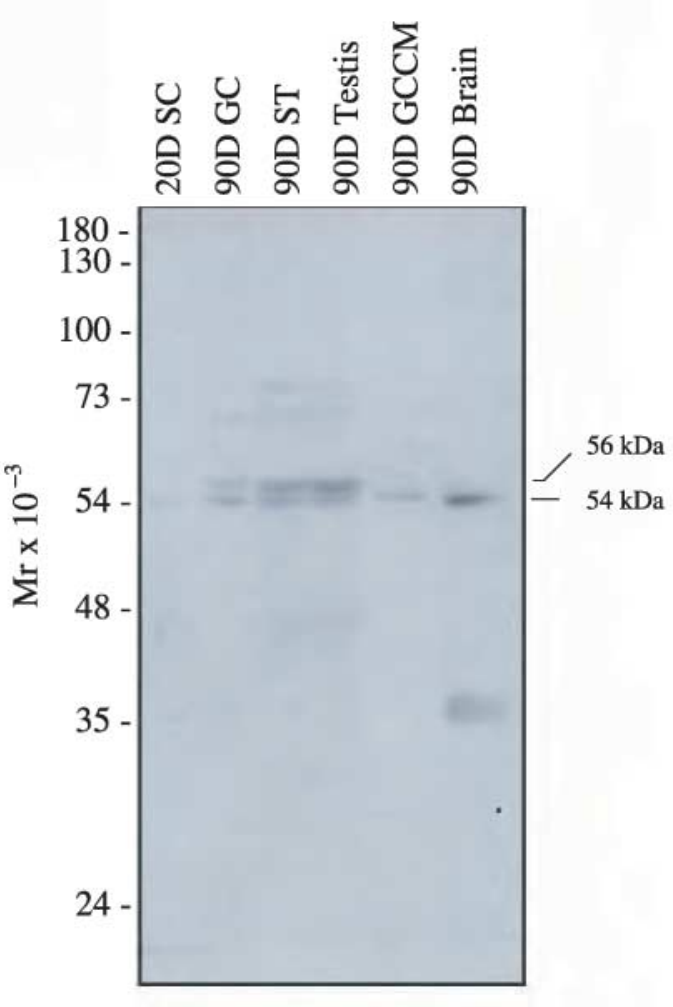

333
D H Y T V D V V V A Y Y I T T R I F W W

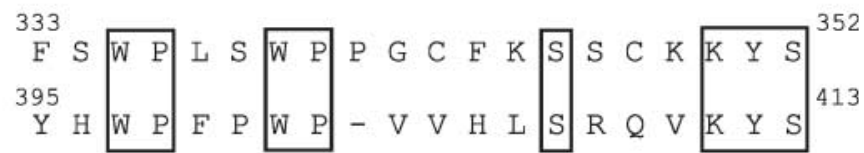

$\mathrm{C}$

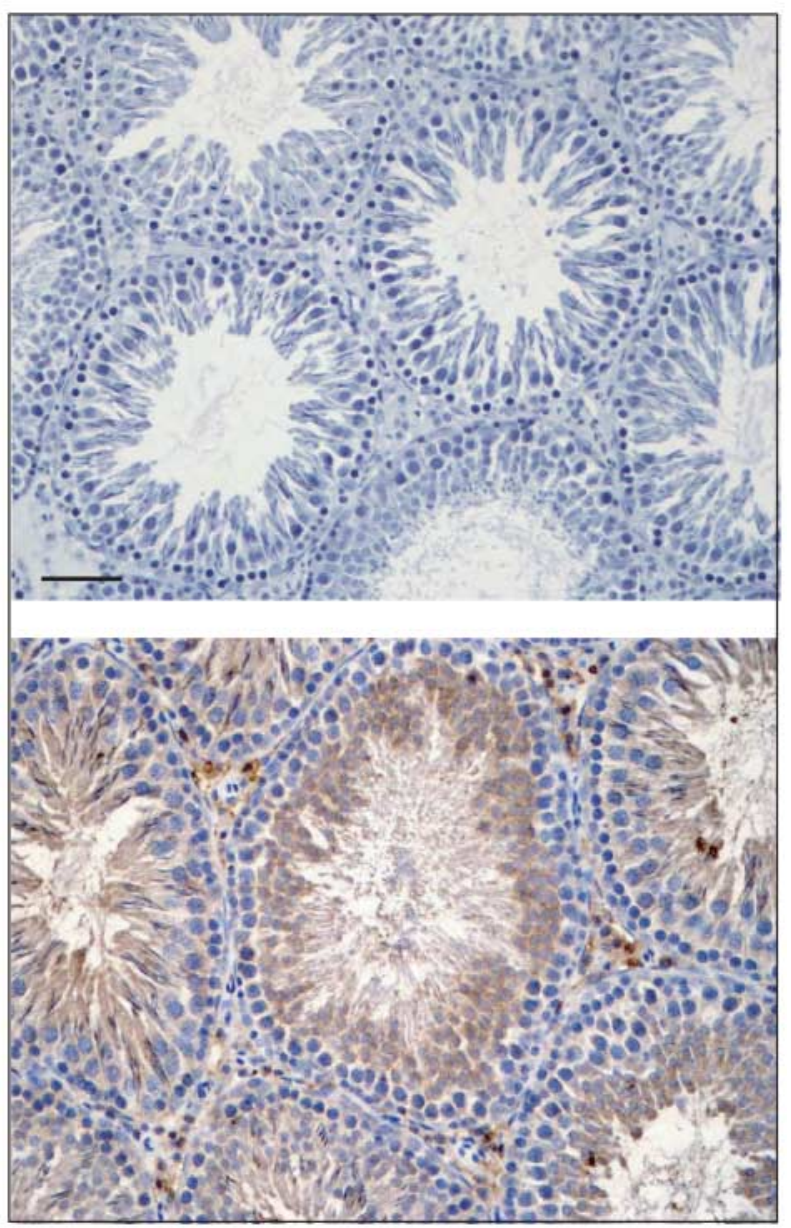

D
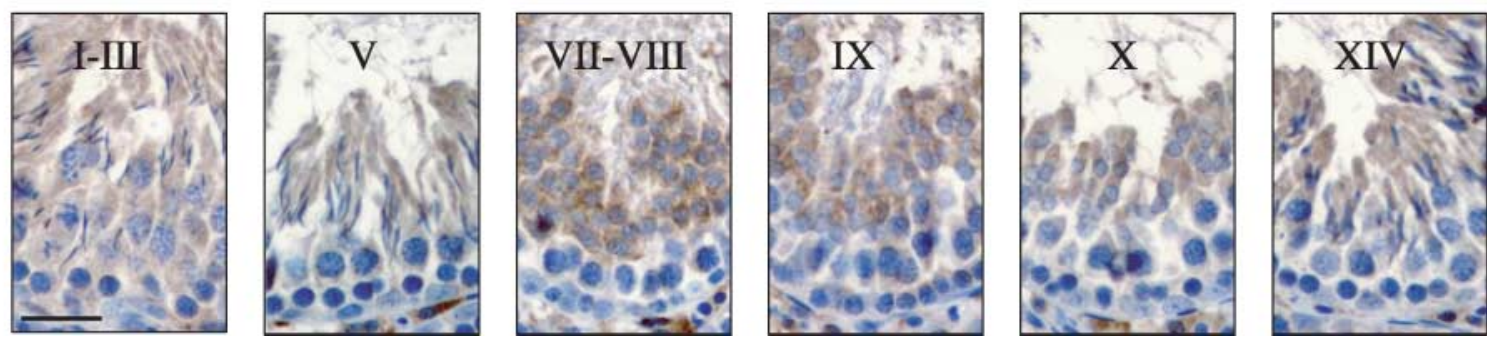
(upper panel in Fig. 3C), illustrating the specificity of the data shown herein (Fig. 3C, upper panel versus lower panel).

Immunofluorescence microscopy The results by immunohistochemistry were consistent with a study using immunofluorescent microscopy to localize SMS2 in the seminiferous epithelium of adult rat testes (Fig. 4). Using this technique, SMS2 was clearly shown to localize at the heads of round spermatids possibly the site of early acrosomes denoted by green fluorescence (Fig. 4A and B). The boxed area in Fig. 4A was magnified and shown in Fig. 4B. SMS2 (green fluorescence) was also detected in the interstitium associated with Leydig cells. However, when the pre-immune IgG was used instead of the anti-SMS2 IgG, no visible green fluorescence was found to associate with developing acrosomes (Fig. 4C) in two stage VII tubules as seen in Fig. 4D by DAPI staining. The weak staining of SMS2 associated with elongating spermatids that was detected by immunohistochemistry (Fig. 3C and D), but was not detected by immunofluorescence microscopy (Figs 3C and D versus $4 \mathrm{~A}$ and $\mathrm{B}$ ) would likely be the result of the differences in the sensitivity of the two techniques.

Immunogold electron microscopy We next sought to use immunogold electron microscopy to examine if SMS2 was indeed localized to the early acrosomes in round spermatids as shown in Fig. 5. Using this technique, immunoreactive SMS2 appears as 'black dots' in the electron micrographs shown in Fig. 5. The early acrosomes (labeled as Ac in Fig. 5) of two round spermatids were clearly visible in Fig. 5A and B, and immunoreactive SMS2 was indeed associated with developing acrosomes. For instance, SMS2 that appears as 'black dots' was found in the entire early acrosomal region as shown in Fig. 5A-C with some SMS2 also found in the plasma membrane (see Fig. 5C), but very few SMS2 'dots' were detected in other parts of the epithelium (see Fig. 5A-C). In more mature elongating spermatids, SMS2 was also shown to associate with the entire acrosomal region and some SMS2 was also detected in the nucleus as shown in Fig. 5D. However, fewer 'dots' were detected in more advanced spermatids as shown in Fig. 5E. Again the number of SMS2 'dots' in other parts of the epithelium in the micrographs shown in Fig. 5D and $E$ is visibly lower than in the acrosomal region (Fig. $5 \mathrm{D}$ and $\mathrm{E}$ ). We conclude that the staining shown in Fig. 5A-E was specific to SMS2 based on two lines of evidence. First, very few SMS2 'black dots' were found outside the developing acrosome and the plasma membrane in sections stained with the anti-SMS2 IgG (see Fig. 5A-E). Secondly, virtually no SMS2 'black dots' were visible when sections of developing spermatids were stained with the pre-immune $\operatorname{IgG}$ as shown in Fig. 5F-H. In short, results of this immunogold electron microscopy study have greatly strengthened data of the study using fluorescent microscopy and immunohistochemistry (see Figs 5 versus 3 and 4).

\section{Spatial correlation of SMS2 with AJ proteins, E-, and $N$-cadherins in adult rat testis}

In order to investigate any possible spatial correlation between SMS2 and other proteins in the seminiferous epithelium, a co-localization study using dual fluorescent probes was used to examine any possible co-localization between SMS2 and E-cadherin (Fig. 6A-C) or N-cadherin (Fig. 6D-F) in adult rat testes. $\mathrm{N}$ - and $\mathrm{E}$-cadherins are two well-studied AJ proteins found most abundantly at the basal ectoplasmic specialization (a testis-specific actin-based adherens junction type between adjacent Sertoli cells at the blood-testis barrier) and with some presence at the apical ectoplasmic specialization (a testis-specific actin-based adherens junction type between Sertoli cells and elongating/elongate spermatids in adult rat testes) at stages V-VI of the epithelia cycle (Johnson \& Boekelheide 2002, Lee \& Cheng 2004). As noted in Fig. 6A and D for the localization of Eand $\mathrm{N}$-cadherins respectively, these two cadherins were localized predominantly at the basal ES at the BTB; yet visible cadherins staining was detected along the Sertoli cell stalks at the apical ES (Fig. 6A and D). However, no observable co-localization between SMS2 and E- (Fig. 6B and C) or N-cadherins (Fig. 6E and F) was detected, suggesting that SMS2 was spatially segregated with those cadherin-based AJ complexes in the testes.

Figure 3 (A-D) A study by immunohistochemistry to examine the cellular localization of SMS2 in the seminiferous epithelium of adult rat testes. (A) This figure summarizes the results of the sequence homology search between SMS2 and SMS1 at the stretch of sequence, amino acid residues 333-352, which was used to generate a polyclonal antibody for immunoblotting and immunohistochemistry studies shown in B-D. We also compared SMS2 at residues 333-352 with SMS1 at residues 395-413. The boxed area in (A) represents identical amino acid residues between these two stretches of sequences. (B) This is an immunoblot that was used to illustrate the specificity of the anti-SMS2 IgG, which was purified from the anti-serum by sequential ammonium sulfate precipitation and diethylaminoethyl (DEAE) anion-exchange chromatography (Cheng et al. 1988). Lysates (approximately $100 \mu \mathrm{g}$ total protein) from Sertoli cells (SC), germ cells (GC), seminiferous tubules (ST), and testes obtained from rats of specified ages (D, day) versus brain were resolved by SDS-PAGE and stained by using the antiSMS2 IgG. GCCM (approximately $20 \mu \mathrm{g}$ protein) is the germ cell-conditioned media obtained from 90-day-old germ cell cultures (terminated within $16 \mathrm{~h}$ ). A prominent band with an electrophoretic mobility corresponding to SMS2 at $54 \mathrm{kDa}$ and a variant of $55 \mathrm{kDa}$ were detected. (C and D) The localization of SMS2 in the seminiferous epithelium of adult rat testes was investigated by immunohistochemistry using the anti-SMS2 IgG characterized in (B). SMS2 was found to associate with round spermatids and early elongating spermatids but not late elongate spermatids (lower panel in C and D), and with the most intense staining in staged VII-VIII tubules with the developing round spermatids (D). Only very weak staining of SMS2 was detected in late elongate spermatids in stages VII-VIII tubules. Negative control was performed using pre-immune normal rabbit IgG to substitute the SMS2 polyclonal antibodies (C, upper panel). The micrographs shown herein are representative results of a single experiment. However, this study was repeated six times by two different investigators in this laboratory using samples from different rats and similar results were obtained. Bar in $C=80 \mu \mathrm{m}, D=20 \mu \mathrm{m}$. 

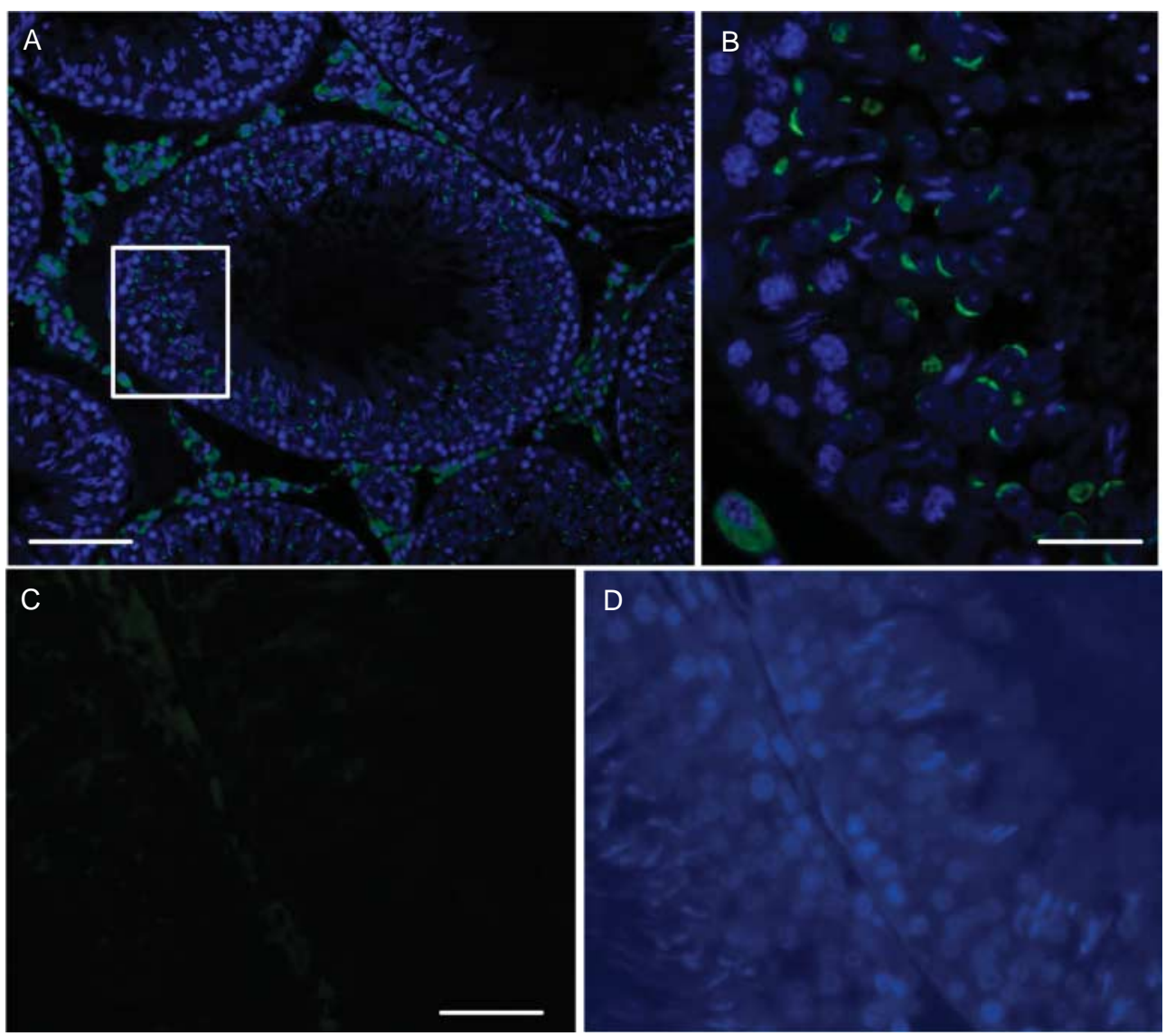

Figure $4(A-D)$ Localization of SMS2 in the seminiferous epithelium of rat testes by immunofluorescence microscopy. Paraffin-embedded rat testes were prepared and subjected to immunofluorescent microscopy using the rabbit anti-SMS2 IgG polyclonal antibody. FITC-conjugated anti-rabbit secondary antibodies were used to visualize the localization of SMS2, as indicated by green immunofluorescence. Blue immunofluorescence was DAPI, denoting the location of the nuclei. The boxed area in (A) was magnified and shown in (B). (C) and (D) are the corresponding control experiments where testes sections were stained with the pre-immune IgG instead of the anti-SMS2 IgG with non-detectable SMS2 (green fluorescence) (C), and the two stage VII tubules shown by DAPI staining (D). Besides its localization at the developing acrosome (B), SMS2 was also detected in Leydig cells in the interstitium (see A and B). These are representative micrographs of a single experiment, which was repeated three times using sections from different rat testes with similar results. Bar in $A=80 \mu \mathrm{m}, B=20 \mu \mathrm{m}$, and $C=30 \mu \mathrm{m}$ which applies to $D$.

These results also suggest that while SMS2 was restricted to the developing acrosomes found in spermatids as shown in Fig. 5A$\mathrm{C}$, which is also the site of apical ectoplasmic specialization, SMS2 is not an adherens junction protein.

\section{Induction of SMS2 during Adjudin-induced AJ restructuring and disruption}

It is known that treatment of rats with Adjudin at $50 \mathrm{mg} / \mathrm{kg}$ b.w. through gavage would induce extensive AJ restructuring, leading to germ cell depletion from the seminiferous epithelium, most notably elongating/elongate spermatids, to be followed by round spermatids and spermatocytes (Cheng et al. 2001, Chen et al. 2003). Interestingly, while SMS2 is not an anchoring junction protein, studies by immunoblotting have shown that a surge in SMS2 protein level was detected as early as $4 \mathrm{~h}$ after Adjudin treatment which persisted until day 4 when most germ cells had dislodged from the epithelium, and its level declined rapidly thereafter, possibly as a result of germ cells loss since SMS2 is restricted to germ cells in the testis (Fig. 7A). As shown in a study by fluorescent microscopy reported in Fig. 7B, a-c were frozen sections stained with preimmune normal rabbit IgG (negative controls), while SMS2 staining was not detected, the DAPI staining for nuclei has illustrated normal morphology of the tubules (a and c). In Fig. 7B, d-f represent sections stained with anti-SMS2 IgG, illustrating positive staining for the round and elongating spermatids; however, an increase in SMS2 staining with the depleting elongating and round spermatids was clearly visible by days $1(\mathrm{~g}-\mathrm{i})$ and $2(\mathrm{j}-\mathrm{l})$ post-treatment, even though these 


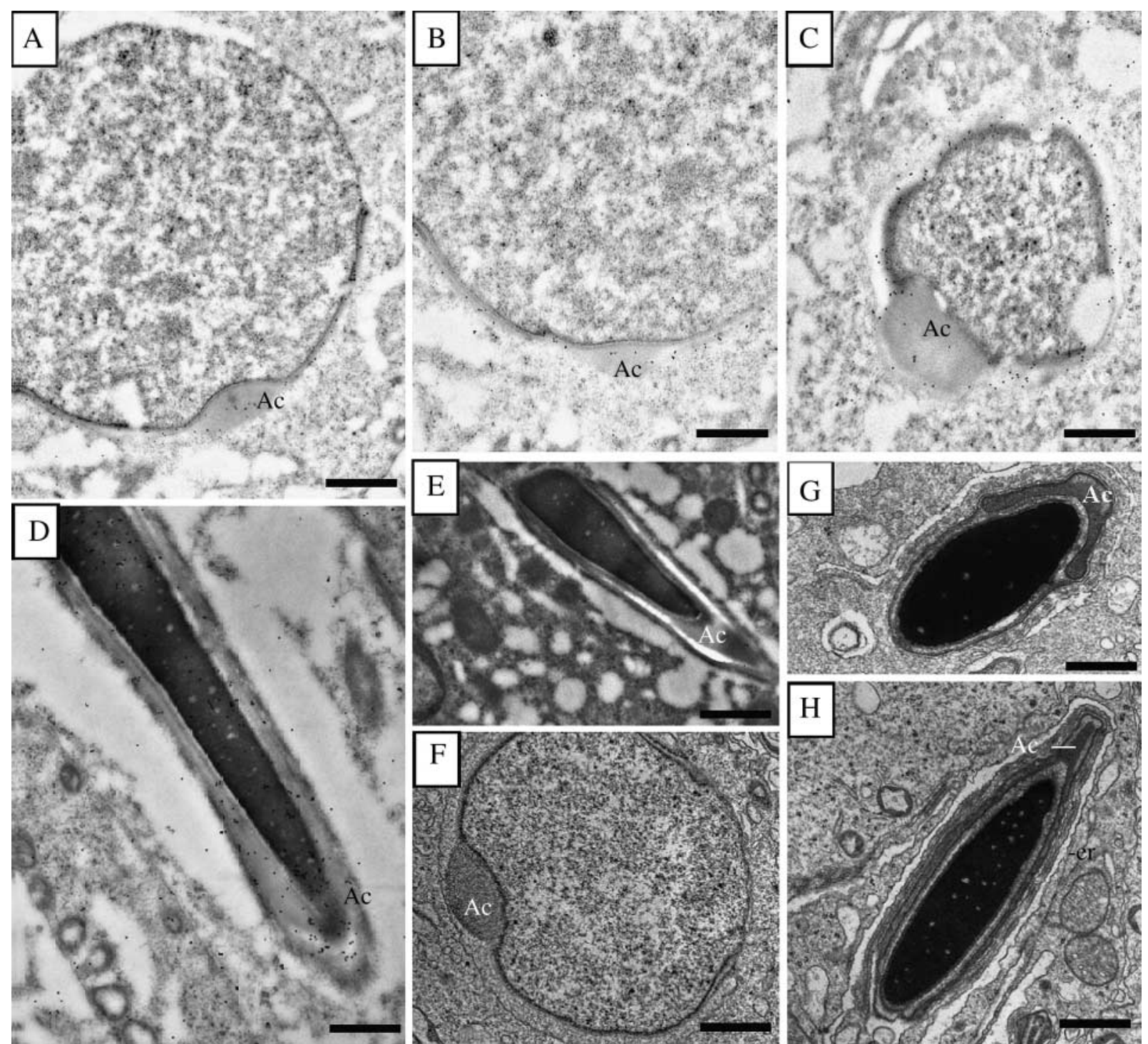

Figure $5(\mathrm{~A}-\mathrm{H})$ Ultrastructural localization of SMS2 in acrosomes and plasma membrane of developing spermatids in the seminiferous epithelium of adult rat testes. Immunogold electron microscopy was performed to localize immunoreactive SMS2, which appear as 'black dots' in developing acrosomes and the adjacent plasma membrane in round spermatids (A-C) as well as in elongating spermatids (D-E) stained with the anti-SMS2 IgG versus controls $(\mathrm{F}-\mathrm{H})$ stained with $\lg \mathrm{G}$ isolated from pre-immune serum. In more developed elongate spermatids, such as shown in E, when the acrosome was well formed, the number of SMS2 'dots' was reduced versus less developed spermatids (see $E$ versus $D$ and $A-C$ ). Bar in $A=0.3 \mu \mathrm{m}$ which applies to $B, D$; bar in $C=0.5 \mu \mathrm{m}$ which applies to $E$, G; bar in $F=0.4 \mu \mathrm{m}$ which applies to $\mathrm{H}$. Ac, acrosome; er, endoplasmic reticulum.

spermatids had been dislodged from the epithelium and were found in the tubule lumen (see $\mathrm{g}-1$ versus $\mathrm{d}-\mathrm{f}$ )).

\section{Discussion}

Based on the results of immunohistochemistry and electron microscopy as reported herein, SMS2 was localized to the apical ectoplasmic specialization site surrounding the heads of the developing spermatids. However, SMS2 does not appear to be a structural apical ectoplasmic specialization protein. First, it did not co-localize with N-, E-cadherins, or espin (data not shown) as shown by fluorescent microscopy. Secondly, a subsequent biochemical analysis by co-immunoprecipitation using different primary antibodies also failed to precipitate SMS2 with either occludin, junctional adhesion molecule-A (JAM-A), JAM-C, N-, E-cadherins, $\beta 1$-integrin, zonula occludens-1 (ZO-1), or $\beta$-catenin (data not shown). While most of these negative data were not shown, they did illustrate that SMS2 is not an anchoring junction protein. On the contrary, SMS2 was intimately associated with the developing acrosomes and the plasma membrane at 

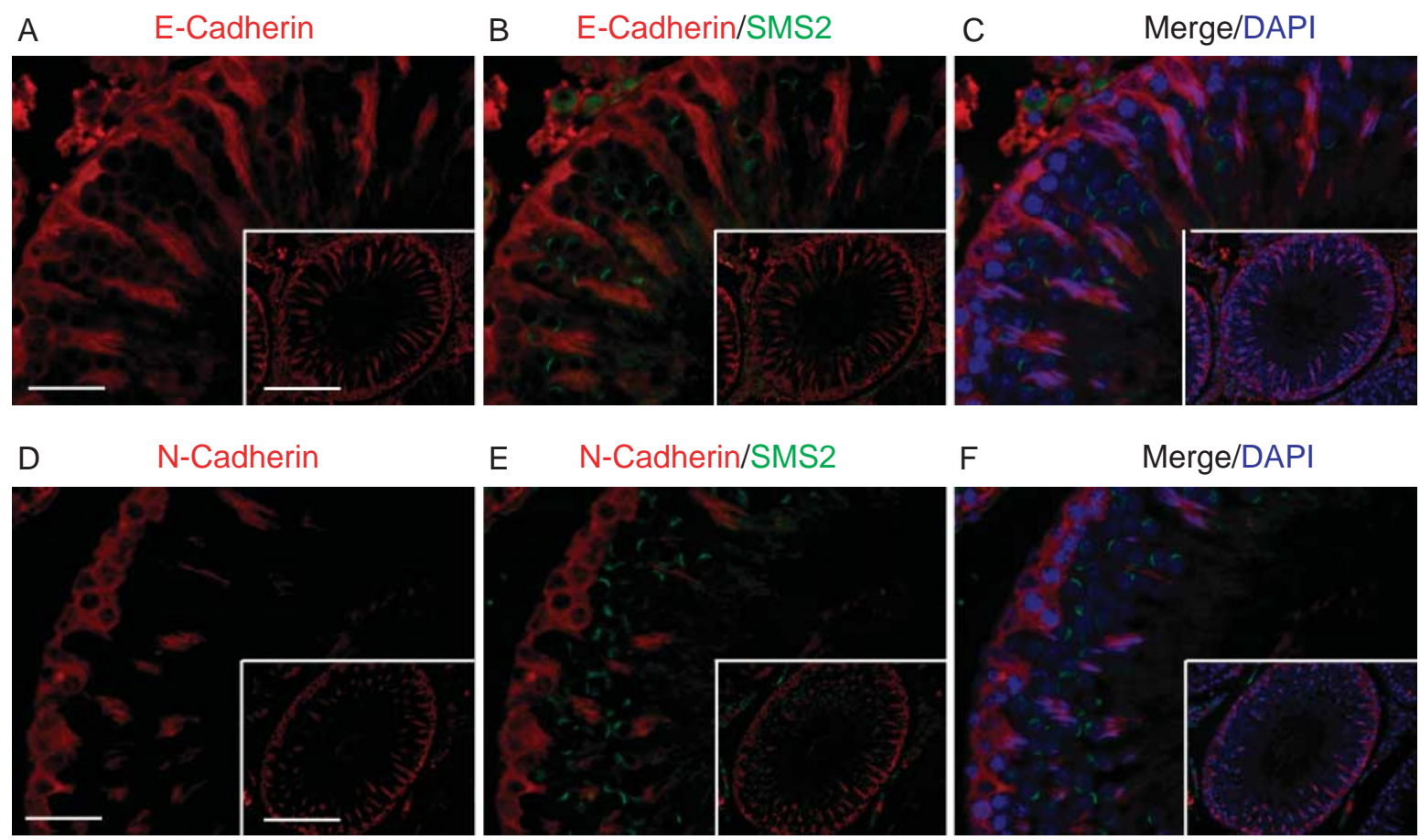

E N-Cadherin/SMS2

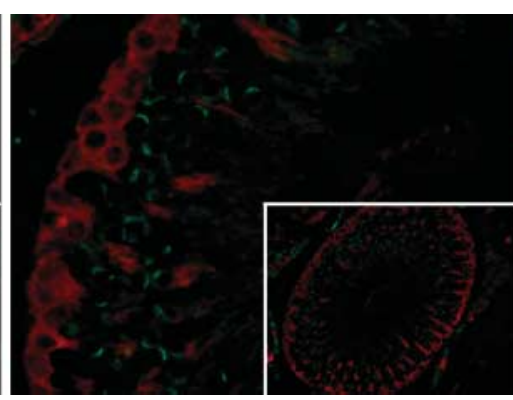

$\mathrm{F}$

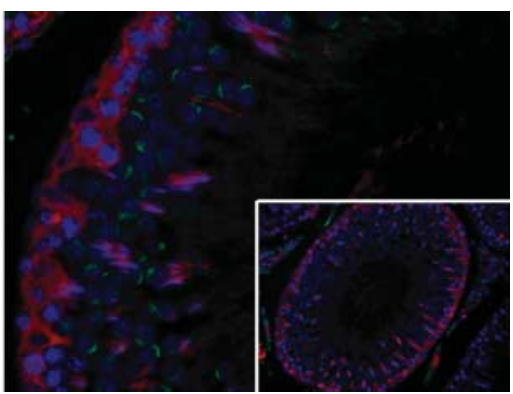

Figure $6(\mathrm{~A}-\mathrm{F})$ The relative localization of SMS2 versus E- and N-cadherins in the seminiferous epithelium of adult rat testes. Paraffinembedded normal rat testes were used for immunofluorescent microscopy. The relative localizations of E-cadherin (A-C), N-cadherin (D-F), and SMS2 in the seminiferous epithelium were revealed by immunofluorescent microscopy using different fluorescent probes. The merged images of E-cadherin (B) and N-cadherin (E) with SMS2 were shown. DAPI was used to localize the nuclei (C and F). The insets in these micrographs represent the low magnified view of the enlarged image in the corresponding micrographs. These micrographs were representative results of a single experiment, which was repeated three times using sections from different rats with similar results. It is noted that negative controls were performed for each of these experiments using normal rabbit IgG instead of both the $\mathrm{N}$ - and $\mathrm{E}$-cadherin antibodies; no detectable fluorescence was detected in each instance (data not shown). Bar in $\mathrm{A}$ and $\mathrm{D}=40 \mu \mathrm{m}$ which applies to $\mathrm{B}, \mathrm{C}$ and $\mathrm{E}, \mathrm{F}$ respectively; bar in inset to $A$ and $D=150 \mu \mathrm{m}$, which applies to inset in $B, C$ and $E, F$ respectively.

or near the acrosome, but not with the fully developed acrosomes in elongate spermatids, such as in stage VIII tubules, illustrating its possible involvement in acrosomal development. The acrosome first appears in round spermatids (for a review, see Abou-Haila \& Tulsiani 2000). Its development undergoes several stages, namely the Golgi phase, the cap phase, the acrosome phase, and the maturation phase (Abou-Haila \& Tulsiani 2000). The acrosome is fully developed in the testis before the detachment of spermatozoa from the seminiferous epithelium during spermiation. While extensive changes on sperm surface take place during maturation in the epididymis, the acrosome remains relatively unaltered until spermatozoa are deposited in the female reproductive tract. During capacitation of spermatozoa in the female reproductive tract, the sperm acrosome undergoes acrosome reaction immediately before the sperm-egg interaction. At the time a spermatozoon binds to the zona pellucida of the egg, the release of the content in the acrosome reaction facilitates successful penetration of sperm through the zona pellucida on the egg surface and gamete fusion (Tulsiani et al. 1998). Within the acrosome, enzymes and proteases coordinate the acrosome maturation and the acrosome reaction (Breitbart \& Spungin 1997, Tulsiani et al. 1998).

SMS2, similar to SMS1, is an enzyme that catalyzes the bidirectional conversion of PC and ceramide to SM and DAG and vice versa (Huitema et al. 2004, Perry \& Ridgway 2005). SMS1 and SMS2 share approximately 57\% sequence homology with each other regarding their primary amino acid sequence and are highly conserved in mammals

Figure 7 ( $A$ and $B$ ) Changes in the steady-state protein level of SMS2 during Adjudin-induced AJ restructuring and germ cell loss in the adult rat testis. (A) Protein lysates were prepared from rat testes isolated from different time points after treatment with Adjudin for immunoblotting using an anti-SMS-2 IgG, illustrating a surge in SMS2 level between $4 \mathrm{~h}$ and 4 day post-treatment. These observations were further confirmed by immunofluorescent microscopy using frozen rat testes sections prepared from selected time points after Adjudin treatment (B). a-C, negative control using IgG isolated from pre-immune serum instead of the anti-SMS2 IgG; d-f, normal rat testes at $0 \mathrm{~h}(0 \mathrm{H})$ stained with anti-SMS2 IgG; g-i, testes by 1 day ( 1 D) post-treatment stained with anti-SMS2 IgG; j-I, testes by 2 day (2 D) post-treatment stained with anti-SMS2 IgG. Green fluorescence represents SMS2 staining and blue DAPI corresponds to nuclei staining. Bar in (a) $=80 \mu \mathrm{m}$, which applies to (b)-(I). 


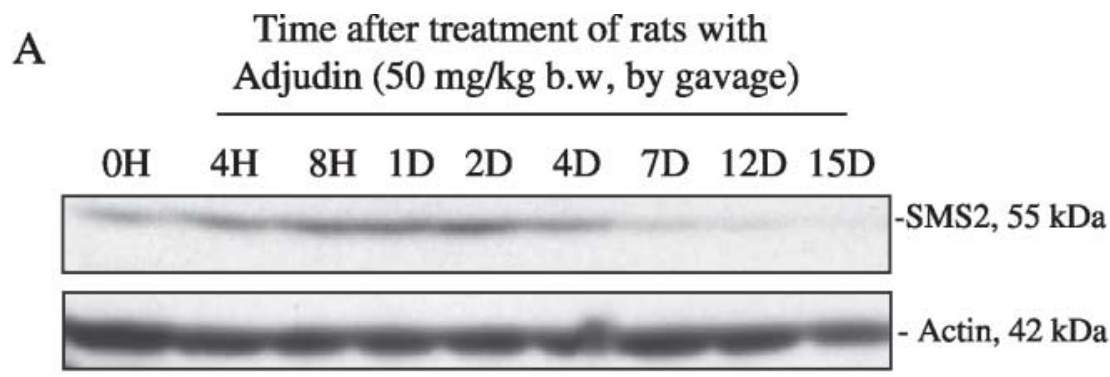

B

Merge
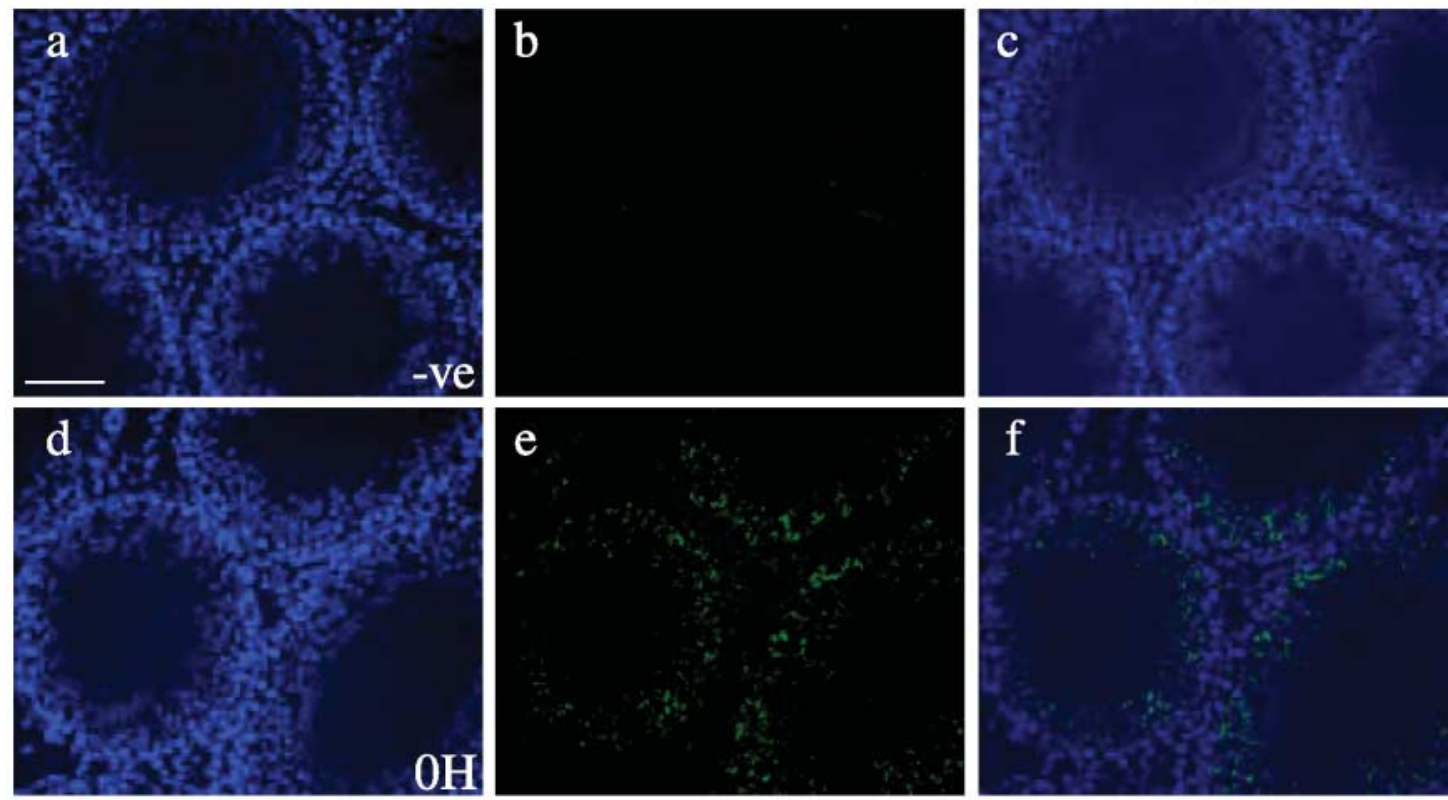

e
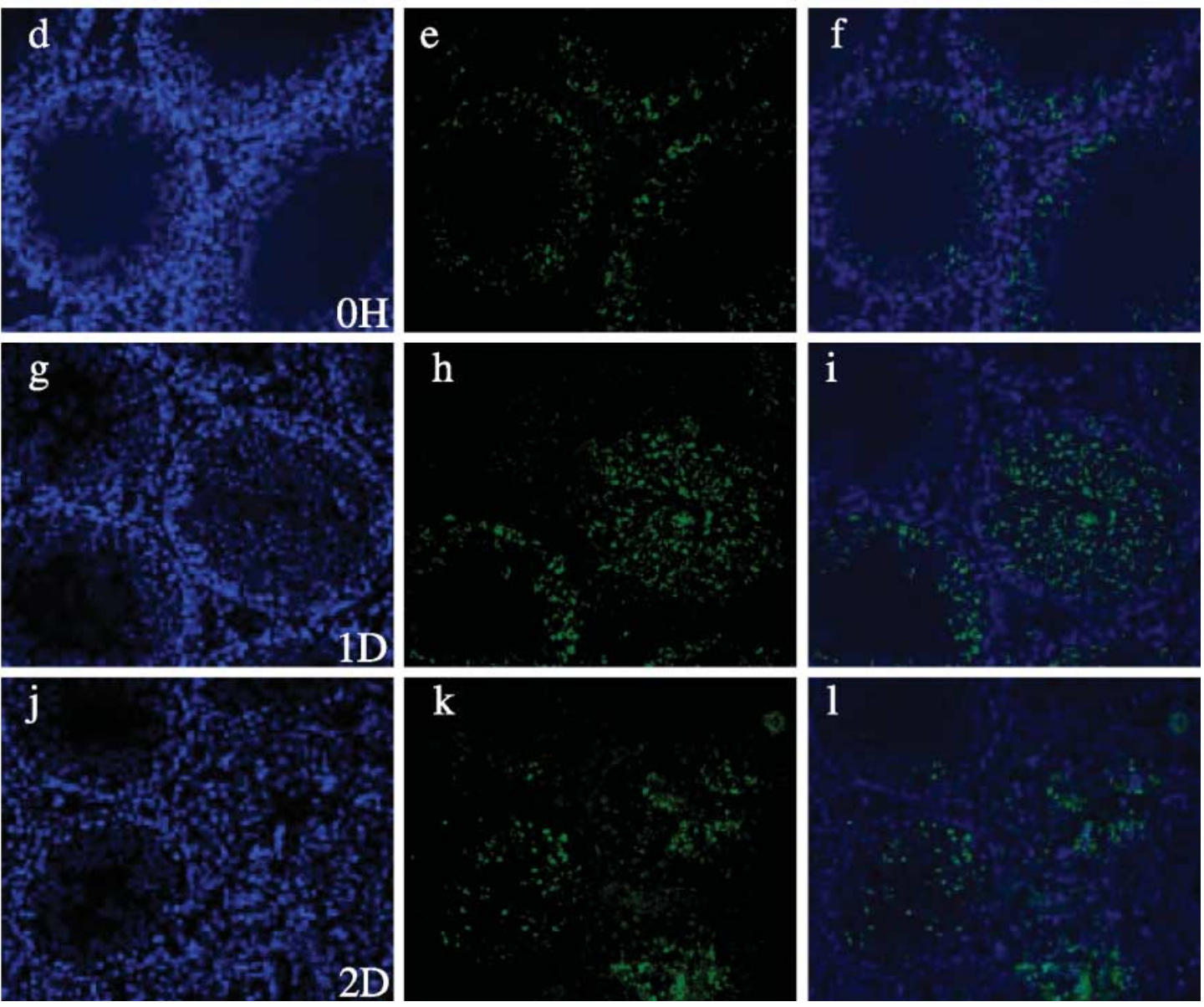
(Huitema et al. 2004). Similarly, both SMS1 and SMS2 express ubiquitously in humans and both possess six transmembrane domains and four highly conserved sequence motifs. Despite these similarities, they are found in different cellular compartments in most epithelia, for instance, SMS1 resides mostly in the Golgi, while SMS2 is found on the plasma membrane (Huitema et al. 2004). Our data have shown that SMS2 in the seminiferous epithelium are indeed associated with plasma membrane of developing spermatids mostly at the region of the developing acrosome as shown in the study using immunogold EM, consistent with the results of immunofluorescence microscopy. This difference of cellular localization of SMS1 and SMS2 in epithelia also accounts for the fact that the bulk of cellular SM is produced by SMS1; however, SMS2 has been demonstrated to possess putative SM synthesis capability (Tafesse et al. 2006). Two truncated forms of mouse SMS1 have been discovered (Tafesse et al. 2006); however, it is still not known whether alternative splicing also occurs in SMS2 to explain the two visible bands on the immunoblot as shown in this study, or whether they are simply the molecular variants of SMS2 and are the result of differential glycosylation. To the best of our knowledge, this is the first report that demonstrates the presence of SMS2 in the testis even though SM has been found in the Sertoli cells (Ziulkoski et al. 2001a,b). At least two SMs were shown to be synthesized in the Golgi apparatus and the plasma membrane in the Sertoli cells (Ziulkoski et al. 2001a,b). In general, SM is a major component of plasma membranes, associated with a large variety of cellular functions, such as the membrane structuring and the trafficking (Ridgway 2000, Tafesse et al. 2006). In addition, sterol balance mechanism and transmembrane transport are two other functions associated with SM synthesis and turnover (Tafesse et al. 2006). Interestingly, SMS2 was found to be predominantly expressed by germ cells, in particular round and elongating, but not elongate spermatids in adult rat testes instead of the Sertoli cell. These observations suggest a possible physiological link between the Sertoli and the germ cells in the seminiferous epithelium regarding the homeostasis of SM. Although, no transporter has been identified in the testis that mediates the intercellular transport of SM between the Sertoli and the germ cells, similar SM transporters are present in other epithelia. For instance, SM-transferring protein has been identified in chick liver (Westerman et al. 1995) and phosphatidylinositol-transfer protein- $\beta$ has been reported in peripheral blood lymphocytes (de Vries et al. 1995), both of these are known SM transporters. While these may be the putative transporters in testes, their presence in the testis remains to be identified. Since immunoreactive SMS2 (and perhaps SMS1, which remains to be demonstrated) was detected in residual bodies associated with the dislodging of elongate spermatids from the seminiferous epithelium by immunohistochemistry as reported herein, and residual bodies formed during the late stage of spermiogenesis are known to be phagocytosed by the Sertoli cells (Kerr \& de
Kretser 1974, Abou-Haila \& Tulsiani 2000), the SM that were found in the Sertoli cells might be the result of this process. This possibility should be vigorously investigated in future studies. For the localization of SMS2 in the interstitium, we postulate that SM synthesized by SMS2 has an additional role in steroid metabolism. Since Leydig cells are the predominant site for the synthesis of testosterone, whose secretion and production might be subjected to modulation through alterations of lipid metabolism. This might indeed be the role of SM in coordinating the physiological events that occur in Leydig cells regarding steroidogenesis, since lipid metabolism is known to be fine-tuned by SM (Tafesse et al. 2006). However, this possibility must be carefully examined in future studies.

It is highly likely that SMS2 is involved in lipid metabolism associated with acrosome formation. Indeed, SMS has been shown to take part in regulating membrane fluidity and lipid dynamics by altering the levels of SM, ceramide, and DAG, and the bioactive lipids (Huitema et al. 2004, Perry \& Ridgway 2005). Lipid metabolism is an essential cellular process in spermatogenesis, facilitating the distribution and relocation of membrane components in the seminiferous epithelium during germ cell maturation. It also monitors the lateral distribution of surface components in spermiogenesis, similar to those exhibited in other systems (Tocanne et al. 1989). For instance, the diffusing properties of plasma membrane of elongate spermatids are not as good as those exhibited in round spermatids and/or pachytene spermatocytes (Wolf et al. 1986), since these more primitive germ cells undergo extensive cellular re-shaping and orientation, such as the formation of the acrosome typical of elongate spermatids and spermatozoa (Tulsiani et al. 1998, Abou-Haila \& Tulsiani 2000). Apart from membrane regionalization, membrane fusion is another unique feature in spermatogenesis. During spermiogenesis, the fusion of the proacrosomal granules is necessary for acrosome assembly (Ramalho-Santos et al. 2002). Due to the intrinsic functions of SMS2 in catalyzing lipid dynamics, it is highly likely that SMS2 shares some of the roles in regulating the lipid diffusion and the membrane restructuring during spermatid maturation.

Numerous acrosome-associated proteins are known to be crucial to spermatogenesis, and dysfunction or deficiency of these proteins would lead to infertility due to the inability of the testis to generate functional spermatozoa. For instance, the expression of a spermatocyte/spermatid-specific thioredoxin-3 was shown to be significantly reduced in aberrant spermatogenesis (Jimenez et al. 2004). In addition, the inability of spermatozoa to undergo acrosome reaction is clinically known to be one of the causes of male infertility (Benoff 1997). On the other hand, an imbalance of the components of the SMS pathway triggers tumorigenesis and/or abnormal metabolism in other organs. For example, in a study using human prostatic adenocarcinoma cell lines, it was shown that a high SM level was associated with the metastatic index of the cancer cells (Dahiya et al. 1992). Besides, an altered level of SM was found in multidrug resistant ovarian cancer cells (Veldman et al. 2002). 
At present, the physiological significance is not known regarding the significant surge in SMS2 expression which was detected during Adjudin-induced germ cell loss from the seminiferous epithelium, however, this may reflect a change in membrane fluidity at the Sertoli-spermatid interface. In short, we have demonstrated the presence of SMS2 in adult rat testis, which is a stage-specific protein and is related to the acrosome development during spermatogenesis.

\section{Acknowledgements}

We are grateful to Ms Helen Shio at The Rockefeller University Bio-Imaging Resource Center for excellent technical assistance in performing studies using immunogold electron microscopy. The nucleotide sequence of the fulllength cDNA encoding SMS2 has been deposited at GenBank with Accession number: DQ071571. This work was supported in part by grants from the National Institutes of Health (NICHD, U01 HD045908; U54 HD029990 Project 3 to C Y C), and the CONRAD Program (CJCCR CIG-01-72). The authors declare that there is no conflict of interest that would prejudice the impartiality of this scientific work.

\section{References}

Abou-Haila A \& Tulsiani DRP 2000 Mammalian sperm acrosome: formation, contents, and function. Archives of Biochemistry and Biophysics 379 173-182.

Bendtsen JD, Nielsen H, von Heijne G \& Brunak S 2004 Improved prediction of signal peptides: SignalP 3.0. Journal of Molecular Biology 340 783-795.

Benoff S 1997 Carbohydrates and fertilization: an overview. Molecular Human Reproduction 3 599-637.

Blom N, Gammeltoft S \& Brunak S 1999 Sequence and structure-based prediction of eukaryotic protein phosphorylation sites. Journal of Molecular Biology 294 1351-1362.

Bradford MM 1976 A rapid and sensitive method for the quantitation of microgram quantities of protein utilizing the principle of protein-dye binding. Analytical Biochemistry 72 248-254.

Breitbart H \& Spungin B 1997 The biochemistry of the acrosome reaction. Molecular Human Reproduction 3 195-202.

Chan YL, Paz V, Olvera J \& Wool IG 1990 The primary structure of rat ribosomal protein S16. FEBS Letters 263 85-88.

Chen YM, Lee NPY, Mruk D, Lee WM \& Cheng CY 2003 Fer kinase/FerT and adherens junction dynamics in the testis: an in vitro and in vivo study. Biology of Reproduction 69 656-672.

Cheng CY \& Mruk DD 2002 Cell junction dynamics in the testis: Sertoligerm cell interactions and male contraceptive development. Physiological Reviews 82 825-874.

Cheng CY, Mathur PP \& Grima J 1988 Structural analysis of clusterin and its subunits in ram rete testis fluid. Biochemistry 27 4079-4088.

Cheng CY, Silvestrini B, Grima J, Mo MY, Zhu LJ, Johansson E, Saso L, Leone MG, Palmery M \& Mruk D 2001 Two new male contraceptives exert their effects by depleting germ cells prematurely from the testis. Biology of Reproduction 65 449-461.

Cheng CK, Cheung CH \& Lee WM 2003 Mouse testin: complementary DNA cloning, genomic organization, and characterization of its proximal promoter region. Biology of Reproduction 68 1376-1386.

Dahiya R, Boyle B, Goldberg BC, Yoon WH, Konety B, Chen K, Yen TS, Blumenfeld W \& Narayan P 1992 Metastasis-associated alterations in phospholipids and fatty acids of human prostatic adenocarcinoma cell lines. Biochemistry and Cell Biology 70 548-554.
Dudeja PK, Dahiya R \& Brasitus TA 1986 The role of sphingomyelin synthetase and sphingomyelinase in 1,2-dimethylhydrazine-induced lipid alterations of rat colonic plasma membranes. Biochimica et Biophysica Acta 863 309-312.

Galdieri M, Ziparo E, Palombi F, Russo MA \& Stefanini M 1981 Pure Sertoli cell cultures: a new model for the study of somatic-germ cell interactions. Journal of Andrology 5 249-259.

Glienke J, Schmitt AO, Pilarsky C, Hinzmann B, Weib B, Rosenthal A \& Thierauch KH 2000 Differential gene expression by endothelial cells in distinct angiogenic states. European Journal of Biochemistry 267 2820-2830.

Huitema K, van den Dikkenberg J, Brouwers JF \& Holthuis JC 2004 Identification of a family of animal sphingomyelin synthases. EMBO Journal 23 33-44.

Jimenez A, Zu W, Rawe VY, Pelto-Huikko M, Flickinger CJ, Sutovsky P, Gustafsson JA, Oko R \& Miranda-Vizuete A 2004 Spermatocyte/spermatid-specific thioredoxin-3, a novel Golgi apparatus-associated thioredoxin, is a specific marker of aberrant spermatogenesis. Journal of Biological Chemistry 279 34971-34982.

Johnson KJ \& Boekelheide K 2002 Dynamic testicular adhesion junctions are immunologically unique. II. Localization of classic cadherins in rat testis. Biology of Reproduction 66 992-1000.

Johnson AD, Gomes WR \& Vandemark NL 1970 The Testis. Development, Anatomy, and Physiology. vol 1, New York: Academic Press.

Julenius K, Molgaard A, Gupta R \& Brunak S 2005 Prediction, conservation analysis, and structural characterization of mammalian mucin-type $O-$ glycosylation sites. Glycobiology 15 153-164.

Kerr JB \& de Kretser DM 1974 Proceedings: the role of the Sertoli cell in phagocytosis of the residual bodies of spermatids. Journal of Reproduction and Fertility 36 439-440.

Lee NPY \& Cheng CY 2003 Regulation of Sertoli cell tight junction in the rat testis via the nitric oxide synthase/soluble guanylate cyclase/cGMP/protein kinase G signaling pathway: an in vitro study. Endocrinology 144 3114-3129.

Lee NPY \& Cheng CY 2004 Ectoplasmic specialization, a testis-specific cellcell actin-based adherens junction type: is this a potential target for male contraceptive development? Human Reproduction Update 10 349-369.

Lee NPY \& Cheng CY 2005 Protein kinases and adherens junction dynamics in the seminiferous epithelium of the rat testis. Journal of Cellular Physiology 202 344-360.

Lee NPY, Mruk DD, Lee WM \& Cheng CY 2003 Is the cadherin/catenin complex a functional unit of cell-cell actin-based adherens junctions $(\mathrm{AJ})$ in the rat testis? Biology of Reproduction 68 489-508.

Lee NPY, Mruk DD, Conway AM \& Cheng CY 2004 Zyxin, axin, and WASP are adaptors that link the cadherin/catenin protein complex to cytoskeleton at adherens junctions in the seminiferous epithelium of the rat testis. Journal of Andrology 25 200-215.

Lyman EM, Dove JL \& Sribney M 1976 Effect of propylthiouracil-induced hypothyroidism on phosphatidylcholine, phosphatidylethanolamine, and sphingomyelin synthesis in chick liver microsomes. Canadian Journal of Biochemistry 54 15-21.

Marggraf WD \& Kanfer JN 1987 Kinetic and topographical studies of the phosphatidylcholine: ceramide choline phosphotransferase in plasma membrane particles from mouse ascites cells. Biochimica et Biophysica Acta $89757-68$.

Martin KJ \& Pardee AB 2000 Identifying expressed genes. PNAS 97 3789-3791.

Moller S, Croning MD \& Apweiler R 2001 Evaluation of methods for the prediction of membrane spanning regions. Bioinformatics 17 646-653.

Monigatti F, Gasteiger E, Bairoch A \& Jung E 2002 The sulfinator: predicting tyrosine sulfation sites in protein sequences. Bioinformatics 18 769-770.

Mruk DD \& Cheng CY 1999 Sertolin is a novel gene marker of cell-cell interactions in the rat testis. Journal of Biological Chemistry 274 27056-27068.

Mruk DD \& Cheng CY 2004a Cell-cell interactions at the ectoplasmic specialization in the testis. Trends in Endocrinology and Metabolism 15 439-447.

Mruk DD \& Cheng CY 2004b Sertoli-Sertoli and Sertoli-germ cell interactions and their significance in germ cell movement in the seminiferous epithelium during spermatogenesis. Endocrine Reviews $\mathbf{2 5}$ $747-806$. 
Mruk DD, Zhu LJ, Silvestrini B, Lee WM \& Cheng CY 1997 Interactions of proteases and protease inhibitors in Sertoli-germ cell cocultures preceding the formation of specialized Sertoli-germ cell junctions in vitro. Journal of Andrology 18 612-622.

Mruk DD, Siu MKY, Conway AM, Lee NPY, Lau ASN \& Cheng CY 2003 Role of protease inhibitor of metalloproteases- 1 in junction dynamics in the testis. Journal of Andrology 24 510-523.

Perry RJ \& Ridgway ND 2005 Molecular mechanisms and regulation of ceramide transport. Biochimica et Biophysica Acta 1734 220-234.

Ramalho-Santos J, Schatten G \& Moreno RD 2002 Control of membrane fusion during spermiogenesis and the acrosome reaction. Biology of Reproduction 67 1043-1051.

Ridgway ND 2000 Interactions between metabolism and intracellular distribution of cholesterol and sphingomyelin. Biochimica et Biophysica Acta 1484 129-141.

Russell L 1977 Movement of spermatocytes from the basal to the adluminal compartment of the rat testis. American Journal of Anatomy 148 313-328.

Russell LD 1980 Sertoli-germ cell interrelations: a review. Gamete Research 3 179-202.

Russell L, Ettlin RA, Sinha Hikim AP \& Clegg EJ 1990 Histological and Histopathological Evaluation of the Testis, pp 1-52. Clearwater, FL: Cache River.

Schultz J, Milpetz F, Bork P \& Ponting CP 1998 SMART, a simple modular architecture research tool: identification of signaling domains. PNAS 95 5857-5864.

Siu MKY, Mruk DD, Lee WM \& Cheng CY 2003 Adhering junction dynamics in the testis are regulated by an interplay of $\beta 1$-integrin and focal adhesion complex-associated proteins. Endocrinology 144 2141-2163.

Tafesse FG, Ternes P \& Holthuis JC 2006 The multigenic sphingomyelin synthase family. Journal of Biological Chemistry 281 29421-29425.

Tocanne JF, Dupou-Cezanne L, Lopez A \& Tournier JF 1989 Lipid lateral diffusion and membrane organization. FEBS Letters 257 10-16.

Tulsiani DRP, Abou-Haila A, Loeser CR \& Pereira BMJ 1998 The biological and functional significance of the sperm acrosome and acrosomal enzymes in mammalian fertilization. Experimental Cell Research 240 151-164.

Veldman RJ, Klappe K, Hinrichs J, Hummel I, van der Schaaf G, Sietsma H \& Kok JW 2002 Altered sphingolipid metabolism in multidrug-resistant ovarian cancer cells is due to uncoupling of glycolipid biosynthesis in the Golgi apparatus. FASEB Journal 16 1111-1113. de Vries KJ, Heinrichs AA, Cunningham E, Brunink F, Westerman J, Somerharju PJ, Cockcroft S, Wirtz KW \& Snoek GT 1995 An isoform of the phosphatidylinositol-transfer protein transfers sphingomyelin and is associated with the Golgi system. Biochemical Journal 310 643-649.

Westerman J, de Vries KJ, Somerharju P, Timmermans-Hereijgers JL, Snoek GT \& Wirtz KW 1995 A sphingomyelin-transferring protein from chicken liver. Use of pyrene-labeled phospholipid. Journal of Biological Chemistry 270 14263-14266.

Wolf DE, Scott BK \& Millette CF 1986 The development of regionalized lipid diffusibility in the germ cell plasma membrane during spermatogenesis in the mouse. Journal of Cell Biology 103 1745-1750.

Wong CH, Xia W, Lee NPY, Mruk DD, Lee WM \& Cheng CY 2005 Regulation of ectoplasmic specialization dynamics in the seminiferous epithelium by focal adhesion-associated proteins in testosterone-suppressed rat testes. Endocrinology 146 1192-1204.

Xia W, Mruk DD, Lee WM \& Cheng CY 2005 Cytokines and junction restructuring during spermatogenesis-a lesson to learn from the testis. Cytokine and Growth Factor Reviews 16 469-493.

Zhang J, Wong CH, Xia W, Mruk DD, Lee NPY, Lee WM \& Cheng CY 2005 Regulation of Sertoli-germ cell adherens junction dynamics via changes in protein-protein interactions of the $N$-cadherin- $\beta$-catenin protein complex which are possibly mediated by c-Src and myotubularinrelated protein 2: an in vivo study using an androgen suppression model. Endocrinology 146 1268-1284.

Ziulkoski AL, Zimmer AR \& Guma FC 2001a De novo synthesis and recycling pathways of sphingomyelin in rat Sertoli cells. Biochemical and Biophysical Research Communications 281 971-975.

Ziulkoski AL, Zimmer AR, Zanettini JS, Trugo LC \& Guma FC $2001 b$ Synthesis and transport of different sphingomyelin species in rat Sertoli cells. Molecular and Cellular Biochemistry 219 57-64.

\section{Received in final form 10 October 2006 \\ Accepted 27 October 2006 Made available online as an Accepted Preprint 30 October 2006}

